\title{
Evaluating Community Coalitions for Prevention of Substance Abuse: The Case of Project Freedom
}

\author{
Stephen B. Fawcett, Ph.D.; Rhonda K. Lewis, Ph.D., M.P.H.; \\ Adrienne Paine-Andrews, Ph.D.; Vincent T. Francisco, Ph.D.; \\ Kimber P. Richter, M.P.H.; \& Ella L. Williams, M.Ed. \\ University of Kansas \\ and \\ Barbara Copple \\ Stratton Associates, Alexandria, VA
}

Running head: Evaluating Substance Abuse Coalitions

Stephen B. Fawcett, Ph.D.

Work Group on Health Promotion

\& Community Development

4086 Dole Center

University of Kansas

Lawrence, KS 66045

Submitted for publication

ABSTRACT

In the United States alone, there are over two thousand community coalitions to address 
local concerns about abuse of alcohol, tobacco, and other drugs. This report describes an evaluation system used to examine the process, outcome, and impact of coalitions for the prevention of substance abuse. The evaluation addresses five key questions: a) Was the community mobilized to address substance abuse (Process)?, b) What changes in the community resulted from the coalition (Outcome)?, c) Is there a change in reported use of alcohol and other substances by youth (Outcome)?, d) Does the coalition have a community-level impact on substance abuse (Impact)?, and e) Is community-level impact related to changes facilitated by the coalition (Impact)? To address these and other questions, the evaluation system collects 15 distinct measures using eight core measurement instruments. This evaluation system is illustrated with a multi-year study of Project Freedom, a substance abuse coalition in a large midwestern city. 


\section{EVALUATING COMMUNITY COALITIONS FOR PREVENTION OF SUBSTANCE ABUSE: THE CASE OF PROJECT FREEDOM}

In response to community concern and available funding, over two thousand communities have mobilized local citizens to reduce the risk of substance abuse. ${ }^{12}$ These initiatives, often referred to as community coalitions, are alliances among representatives of different sectors, organizations, or constituencies for a common purpose such as reducing substance abuse. Coalitions serve as a catalyst: they attempt to change the programs, policies, and practices of sectors of the community that contribute to the abuse of alcohol, tobacco, and other drugs.

Applied scientists attempt to combine research and action in their collaborations with community coalitions. ${ }^{3}$ This model of evaluation research has two aims. ${ }^{4}$ understanding how coalitions function and improving coalition efforts. Such research integrates quantitative and qualitative methods ${ }^{5}$ in a context of action research. ${ }^{6}$ It assesses the dynamic interactions and consequences of the development process, feeding back this information to improve functioning.

A comprehensive evaluation of community coalitions helps understand and improve coalition process, outcome, and impact. First, it examines the process of coalition building, investigating the pattern of actions taken to bring about change. Second, it studies the outcome of coalition efforts, including whether there was a change in the community's programs, policies, and practices related to substance abuse or in reported use of alcohol and other drugs. Finally, it examines the impact of community coalitions, whether changes in community-level indicators, such as the incidence of single-nighttime vehicle crashes, suggest an overall effect.

This manuscript describes a case study using a comprehensive system for evaluating community coalitions. ${ }^{7}$ This research was part of a collaborative relationship between a university research team and staff of Project Freedom, a substance abuse coalition in Wichita, Kansas. First, we describe the coalition and the framework used to guide the evaluation. 
Second, we outline the evaluation system. Third, we address five key questions related to the evaluation of substance abuse coalitions. Fourth, we review important secondary findings on coalition functioning. Finally, we conclude with a discussion of the challenges and opportunities of evaluating community coalitions for the prevention of substance abuse.

\section{THE CONTEXT AND FRAMEWORK FOR THE EVALUATION}

This section describes the context of this case study, a substance abuse coalition known as Project Freedom. We also outline the framework used to evaluate substance abuse coalitions.

\section{Context of Project Freedom}

Begun in 1989, Project Freedom is a community coalition with the mission of reducing the use of illegal drugs, tobacco, and alcohol among children and adolescents between the ages of 12 and 17 years in the city of Wichita, Kansas (pop. 311,300) and overall Sedgwick County (pop. 403,662). (Although Project Freedom continues in modified form, this report describes the coalition's activities under the leadership of the original executive and associate directors.) Initial financial support for the coalition came from the Wichita Public Schools (USD 259), and

planning and implementation grants from the Kansas Health Foundation. Project Freedom was composed of nearly 100 organizations and over 750 individuals with an interest in reducing use and abuse of alcohol and other drugs.

Project Freedom used both top-down and bottom-up strategies. ${ }^{8}$ It involved key influentials from the community, such as the mayor and county sheriff, as well as grassroots leadership, such as clergy from prominent African-American congregations. The coalition attempted to serve as a catalyst, not as a service agency. Its aim was to bring about changes in programs, policies, and practices that would reduce risk. This required the development of task forces that represented multiple sectors of the community, such as schools, social service organizations, and criminal justice. 


\section{Framework for the Evaluation}

The Work Group system for evaluating coalitions is linked to a conceptual framework for promoting health and community development, ${ }^{8,}{ }^{9}$ and earlier experience designing monitoring and feedback systems for coalitions. ${ }^{10}$ This evaluation framework reflects the four phases of coalition development: a) planning, in which a mission statement, objectives, strategies, and action plans are developed, b) intervention, in which coalition staff and membership take action with targets and agents of change in relevant sectors of the community such as schools or criminal justice, c) changes in the community that reduce risk and enhance protective factors, and d) changes in intermediate and ultimate outcomes, such as reported use of substances and community-level indicators such as single-nighttime vehicle crashes.

\section{THE WORK GROUP EVALUATION SYSTEM}

To address key questions, the Work Group evaluation system collects 15 distinct measures using eight core measurement instruments: a) a monitoring and feedback system, b) constituent surveys about coalition goals, process, and outcome, c) a goal attainment report, d) behavioral surveys, e) interviews with key participants about critical events in the history of the coalition, and f) community-level indicators of impact. Figure 1 outlines the measures, and related methodologies, for assessing coalition process, outcome, and impact. Each core methodology is described in the sections that follow.

Insert Figure 1 about here.

\section{Monitoring and Feedback System}

As detailed elsewhere, ${ }^{10}$ the monitoring and feedback system has three central elements: a) process and outcome measures, b) an observational system for collecting these measures, and c) regular feedback on performance to coalition leadership, funding partners, and other interested audiences. The elements were developed by the Work Group and adapted for this case study in 
collaboration with coalition leadership and representatives of the Kansas Health Foundation. Coalition leadership helped collect data for the monitoring system. Work Group researchers scored the data, graphed it, and communicated the data to coalition membership and funding partners.

Process and outcome measures. Table 1 provides abbreviated definitions and examples of the eight measures collected with the monitoring system. These measure coalition process and outcome, including the number of a) members participating, b) planning products, c) instances of media coverage, d) financial resources generated, e) dollars obtained, f) services provided, g) community actions, and h) community changes.

Two measures obtained with the monitoring system--community actions and community changes--may be particularly sensitive to coalition functioning. If coalition members act outside the group (take community actions), they can produce changes in programs, policies and practices (community changes) that reduce risk and enhance protective factors such as an afterschool program that increases supervision. It is hypothesized that ultimate impact, such as assessed by community-level indicators, may be related to the cumulative impact of community change.

Insert Table 1 about here.

Observational system. Key participants within Project Freedom, such as the executive and associate directors, used event logs to record monitoring data. Completed event $\operatorname{logs}$ provided information about: a) the program or objective for which actions were taken, b) actions (what was done), c) date of action or outcome (when), d) target of action (to or with whom), e) actors' names (by whom), f) the location of the action (where), and g) the outcome achieved (change in program, policy or practice). The logs were mailed to the evaluators. Evaluators called key participants to clarify the information and check for completeness. 
Coding sheets and written definitions were used to score the data recorded on the logs. A graduate research assistant reviewed the logs and scored recorded events as an instance or noninstance of one of the eight process and outcome measures of interest. A small sample of the events and outcomes were also verified, usually by reviewing permanent products such as newspaper articles or minutes of meetings.

Scoring by a second, independent observer permitted an assessment of reliability, or interobserver agreement. A cross-tabulation table was used to indicate the number of events scored accurately and inaccurately. Using Cohen's Kappa, ${ }^{11}$ and observed percent reliability (agreements divided by total number of observations, multiplied by 100 to get percent agreement), the average observed percent reliability for these measures for Project Freedom is 78\% (range 59-96\%; $\mathrm{K}=0.68, \mathrm{p}<0.01$ ). Interobserver reliability was calculated for approximately $85 \%$ of Project Freedom's event logs.

Feeding data back to relevant audiences. The researchers graphed monitoring data and used the graphs to provide updates on progress. Feedback was provided monthly initially, and later quarterly, in meetings with Project Freedom leadership, a program officer from the Foundation, and Work Group researchers. The sessions enabled the collaborators to detect and celebrate early successes, such as a newly established program, that might have required a large number of actions. The data also prompted coalition leadership to report previously unreported events and to consider whether adjustments in the initiative should be made. For example, early evidence suggested that Project Freedom efforts were directed more toward service delivery than community action and change. This engendered a discussion between Project

Freedom leadership, the evaluators, and Foundation program officer regarding whether this distribution of activity was consistent with the group's role as a catalyst for community change.

Coalition staff used these data effectively in newsletters and in meetings with coalition 
members and potential funders. For example, the President's Drug Advisory Council, after reviewing evaluation data on the coalition, featured Project Freedom as one of the five "top" anti-drug coalitions in the country at their National Leadership Forum in Fall, 1991. This national recognition helped solidify local support from political leaders, volunteers, and funding sources.

A data base, listing each event and outcome noted in the graphs, was used to record accomplishments over time. Monitoring data provided a record of coalition accomplishment and helped document coalition functioning and early evidence of success.

\section{Constituent Surveys of Goals, Process, and Outcome}

We used surveys to assess satisfaction with the coalition's action plan (goals), operations (process), and achievements (outcome) from the perspective of constituents. ${ }^{12}{ }^{13}$ The Work Group provided reports to coalition leadership and membership about coalition members' views on the importance of the coalition's goals, satisfaction with the coalition-building process, and the significance of the achievements for reducing substance abuse.

Survey of potential goals. As part of strategic planning process for substance abuse coalitions, ${ }^{14}$ a survey process was used to build consensus on proposed community changes for each sector of the community. Using a 5-point scale $(1=$ low; $5=$ high $)$, ratings of importance and feasibility were collected from each of three types of constituents: coalition members, representatives of the Foundation, and experts in the prevention of substance abuse, such as the state commissioner for alcohol and drug abuse services. Data from coalition members provided the primary basis for setting priorities, with the coalition selecting for proposed changes, such as new programs or policies of relatively high importance and feasibility.

Survey of satisfaction with coalition process. During the third year of Project Freedom's existence, we conducted a survey to assess members' satisfaction with the coalition. Using a 5point scale ( 1 = "very dissatisfied"; 5 = "very satisfied"), survey questions examined aspects of 
planning and implementation, leadership, services, community involvement, and progress and outcome. The survey was used to identify strengths and weaknesses of the coalition process.

Survey of significance of coalition outcomes. An outcome survey was used to assess the significance of community changes resulting from Project Freedom's efforts. A similar 5-point survey was used, with 5 indicating that the community change was very important to the coalition's mission.

\section{Goal Attainment Report}

Staff of the initiative reported whether (and when) proposed changes identified in the action plan were actually accomplished. This information was reviewed by the evaluation team and scored annually as the percentage of original change objectives that

were attained.

\section{Behavioral Surveys}

To further assess the outcomes of the coalition, we obtained and analyzed existing data on behavioral measures of reported use of cigarettes, smokeless tobacco, alcohol, marijuana, and cocaine. Secondary data sources, such as surveys of youth commissioned by the school district, were used to provide behavioral measures of substance abuse.

\section{Interviews with Key Participants}

We used semistructured interviews with active coalition leaders to provide qualitative information about the process, outcome, and impact of Project Freedom. The interviews were conducted several years into the implementation of Project Freedom, and during the transition between leaders of the coalition. The focus of the interviews was to identify and analyze critical events in the history of the coalition, such as securing the initial grant or action planning. Five aspects of each event were considered: a) why it was important, b) the context for the event, c) key actions and actors and other resources, d) barriers and resistance, and e) the consequences of 
the event for the coalition and the community.

\section{Community-level Indicators of Substance Abuse}

Using archival records, Work Group researchers collaborated with city and state-level officials to select and obtain community-level indicators of substance abuse. The most widely recommended community-level indicator of substance abuse is the number of single-nighttime vehicle crashes. ${ }^{15}$ Other potential indicators, such as the number of arrests for driving under the influence of alcohol or other drugs, were either unavailable or seen as less accurate or sensitive.

\section{DATA FOR KEY EVALUATION QUESTIONS}

The evaluation system yields a variety of information, including data for five key questions of importance to the coalition and its funding agents: a) Was the community mobilized to address substance abuse (Process)?, b) What changes in the community resulted from the coalition (Outcome)?, c) Is there a change in reported use of substances by youth (Outcome)?, d) Does the coalition have a community-level impact on substance abuse (Impact)?, and e) Is community-level impact related to changes facilitated by the coalition (Impact)?

\section{Was the community mobilized to address substance abuse?}

We define community mobilization as actions taken by staff, other professionals, and community members affiliated with the coalition to create systems changes, or changes in programs, policies, and practices related to the mission. Figure 2 shows the pattern of community actions taken by coalition members, such as meeting with key leaders in the school system or making phone calls to elected officials about a proposed policy change. The following illustrative events were scored as three different units of community actions: a) meeting with city and parks personnel to develop resources for after school activities for youth such as community service, b) meeting with the Hispanic coalition to help establish a summer youth academy for Hispanic youth, and c) developing a format for a Chaplain inservice for emergency room traumas related to drugs and gangs. 
Insert Figure 2 about here.

Community actions were plotted cumulatively, with each new event added to all previous events. For example, the six new community actions that occurred in September, 1990 were added to the previous total of four actions for a new cumulative total of 10 actions through September 1990. Similarly, the eight new actions that occurred in May, 1991 were added to the previous 40 actions for a cumulative total of 48 through May 1991. With a cumulative record, a flat line depicts no activity or outcome; the steeper the line, the more activity or outcome.

During the initial eight months of planning, the data show low initial rates of community actions since most activity was focused within the coalition. A marked increase and sustained level of community actions followed the completion of the coalition's action plan and hiring of a community organizer in the spring and summer of 1991, respectively. A high and steady rate of community actions continued until the departure of the former executive director in the Fall of 1992 and a loss of key staff, including the associate director, in the summer of 1993. The hiring of a new executive director, who resigned in the spring of 1994, did not appear to bring about equivalent or sustained levels of community action.

Overall, the results show a high level of community mobilization that was sustained for more than two years. Future research may determine whether the coalition can renew its previous levels of community action after a transition to new leadership and the development of a comprehensive new action plan.

\section{What changes in the community resulted from the coalition?}

Figure 3 shows a similar pattern for community change: new or modified programs, policies, or practices related to the mission of preventing substance abuse. For example, the following were recorded as four distinct units of community change: a) Project Freedom implemented the Sedgwick County Youth Community Service program (new program), b) 
Project Freedom, in collaboration with Butler County Community College, earmarked $\$ 25,000$ to establish a scholarship program for at-risk students who may need additional academic support (new program), c) a drive-by shooting ordinance was approved by the city council that increased the penalty to a maximum of one year (new policy), and d) the juvenile court judge agreed to include a DUI victims panel as part of substance abuse sentencing (new practice).

Insert Figure 3 about here.

Community changes occurred only following community actions. After a lag time, most increases in community actions yielded community changes. Although the ratio of community actions to change varied, on the average, slightly more than one action was reported for each community change. Notice the long, steady output of community changes following action planning. The largest increases in community change coincided with the coalition's minigrants program that provided funding for small, new programs, such as a Saturday school program for African-American youth. The lower rates of community change

following the original executive and associated directors' decisions to leave for other positions were not reversed following the hiring of the second executive director.

Overall, the data show a high level of community change that was sustained for more than two years. Future research may determine whether the coalition can reestablish its previous levels of productive community change.

\section{Is there a change in reported use of alcohol and other substances by youth?}

We also obtained data from high school surveys on the percentage of high school seniors reporting regular use of cigarettes, smokeless tobacco, alcohol, marijuana, and cocaine at two points in time (in 1991-92, the second year of implementation; and in 1992-93, the third year). Data from Sedgwick County are compared with statewide data. 
The largest effects were noted with alcohol; showing reductions in reported regular use from $25.1 \%$ to $21.9 \%$ in Sedgwick County compared to $25.2 \%$ to $23.3 \%$ statewide. More modest effects were noted with marijuana; from $7.5 \%$ to $7.1 \%$ in Sedgwick County compared to $6.1 \%$ to $6.2 \%$ statewide. Similarly small effects were noted with cocaine; from $2.1 \%$ to $1.6 \%$ in Sedgwick County compared to $2.0 \%$ to $1.9 \%$ statewide. Reported regular use of cigarettes increased in Sedgwick County from $24.3 \%$ to $25.3 \%$, a slightly higher increase than that observed statewide (from $22.2 \%$ to $22.9 \%$ ). Smokeless tobacco use increased somewhat in Sedgwick County, from $7.1 \%$ to $9.1 \%$, while statewide reported use decreased from $10.2 \%$ to $9.9 \%$.

These findings suggest that the coalition had a modest effect on alcohol use among school-aged youth. Smaller effects may also have occurred with marijuana and cocaine. Statewide increases in cigarette smoking were not reversed by coalition efforts. The substantial rise in smokeless tobacco, and the prevalence of cigarette smoking, suggest the importance of targeting tobacco control as well as abuse of alcohol and other drugs.

\section{Does the coalition have a community-level impact on substance abuse?}

Figure 4 shows archival data on the rate of single-nighttime vehicle crashes, a consensus indicator for assessing community-level impact of substance abuse coalitions. Provided by the state office of traffic safety, these data on crash rate per 1000 are displayed for Sedgwick County, Wyandotte County (a comparison county that includes Kansas City, Kansas), and the state of Kansas. Although the results show no effect in Sedgwick County during the initial planning year (1990), there is a rather marked effect in each of the two years (1991 and 1992) when the coalition's action plan was being implemented as reflected in high and steady levels of community actions and changes.

Insert Figure 4 about here. 
No effects of similar size or duration were observed in either Wyandotte County or the state, although there appears to be a one year decrease in Wyandotte County in 1992 associated with a highway safety grant that added 12 additional motorcycles for the police department. A sharper and more sustained decrease

was observed in Sedgwick County, when compared to Wyandotte County and the state. These preliminary findings suggest that implementation of Project Freedom's action plan, and the community changes that were produced, may have brought about improvements in communitylevel indicators. Of course, other correlated events that occurred before or during the coalition's efforts, such as DUI-prevention grants, may have accounted for the observed changes in community-level indicators.

\section{Is community-level impact related to changes facilitated by the coalition?}

Figure 5 displays the relationship between the community-level indicator, singlenighttime vehicle crashes, and the cumulative number of community changes, a potentially important predictor of ultimate outcome. We hypothesized that improvements in the community-level indicator, a reduction in the crash rate per 1000 , would occur only after a sufficient number of community changes had occurred.

\section{Insert Figure 5 about here.}

The results show that reductions in crash rate occurred only after substantial numbers of community changes were facilitated. During 1990, a planning year in which few community changes were produced, there was a slight increase in crash rate. During 1991 and 1992, the observed decreases in crash rate corresponded with the observed increases in community change. Although the trend for this indicator reversed in 1993 with a slight increase in crash rate, this corresponded with a marked reduction in rate of community changes. These findings suggest that community changes--modifications in programs, policies, and practices related to the 
mission--may have been responsible for improvements in community-level indicators. Sustained rates of community change may be needed to produce (or even maintain) improvement in community-level indicators. Although other events may have caused the observed relationships, this research suggests that community change may be an important intermediate outcome and early predictor of eventual coalition impact.

\section{SECONDARY FINDINGS ON COALITION FUNCTIONING}

Other measures collected by the evaluation system allow examination of additional aspects of the coalition, including: a) Were constituents satisfied with the coalition?, b) Were the community changes important to the mission?, c) Did the initiative attain its goals?, and d) What critical events were associated with changes in the rate of community change?

\section{Were constituents satisfied with the coalition?}

As described earlier, a constituent survey of process was used to provide information on coalition members' satisfaction with various aspects of the coalition, such as competence of staff and leadership. More than 100 coalition members responded. Each item was rated on a 5-point scale, with 5 the highest.

The highest ratings were for the strength and competence of staff (4.1), strength and competence of leadership (4.0), and the clarity of vision for the coalition (4.0). For individual items, the lowest ratings were for training and technical assistance (3.4) and opportunities for coalition members to take leadership roles (3.4). Although the coalition's overall contribution to

the goal of reducing substance use and abuse was rated relatively low at this early stage (2.9), $93 \%$ of those coalition members responding indicated that the community was better off today because of Project Freedom. Since the data were collected during a transition in coalition leadership, the survey data were used to help inform new leadership about the coalition's status and its future challenges. 


\section{Were the community changes important to the mission?}

A constituent survey of outcomes was used to assess the significance of the observed community changes to reducing substance abuse. Over 100 coalition members responded to questions about the importance of each change, using a 5-point scale with 5 the highest.

In general, respondents rated community changes facilitated by Project Freedom as "important," an average rating of 3.8. No community change received a rating below 3.0 (neither unimportant nor important). The top three rated community changes involved changes in resource allocations or policy: the city council approved the addition of 32 police officers (4.4), the city council approved a new "drive-by" shooting ordinance (4.4), and changes in the state law for drive-by shootings (4.4). The lowest ranked community changes involved small, short-term, or symbolic efforts: development of a job description for the director of a state-level commission on family and youth (3.1), a youth project in a local school (3.1), cosponsoring the Great American Smoke-Out to reduce use of tobacco (3.2), and the mayor's commitment to use a drug-free life style slogan on a sticker for all city vehicles (3.2).

Taken together, the contribution of the reported community changes to the mission was rated a 4.2 (between important and very important). Evaluators reported the results to coalition leadership. These survey data were used to help guide choices of objectives in future strategic planning and inform funding agents about the significance of coalition accomplishments.

\section{Did the coalition attain its goals?}

The coalition facilitated a variety of systems changes in the community, many of which were reflected in the original action plan. Evaluators examined how the coalition was progressing in completing the community changes outlined in its action plan.

Researchers graphed the percentage of goals attained that were scheduled for completion for the several years in which Project Freedom's original action plan was operative. Coalition staff and evaluators reviewed the data base of community changes, minutes of meetings, and 
other information to determine which of the original list of community changes to be sought (and others defined by new opportunities) had been accomplished. By the end of 1991, Project Freedom had attained 12 change objectives (more than the eight set for completion according to the original action plan); by the end of 1992, 26 change objectives (more than the original 22). The results suggest that during the several years that Project Freedom's action plan was operative, it remained on or slightly ahead of schedule with accomplishing its goals. By providing feedback on goal attainment, evaluators help

staff and leadership focus attention on the coalition's mission and action plan.

\section{What critical events were associated with changes in the rate of community change?}

Semistructured interviews with coalition leaders and other key participants helped identify critical events that may have influenced the functioning of the coalition. Events identified by informants included ongoing monitoring and feedback, the announcement by Foundation officials that annual renewal of the grant would depend on evidence of progress, action planning, hiring a community organizer, and the departure of the first executive director.

By overlaying the critical events noted during interviews on the monitoring data, possible relationships between events and measures of process and outcome can be examined. For example, as illustrated by Figures $2 \& 3$, since the completion of action planning and the hiring of a community organizer were followed rather immediately by a marked increase in community actions and changes, action planning and competent staff may be among the factors that contributed to community change and impact. Similarly, the departure of the first executive director, and related loss of staff, led to a marked reduction in community actions and changes that did not improve with the hiring of a new executive director. The analysis of critical events helps identify potential factors affecting coalition success. It also helps document the history of the coalition, discover intended and unintended consequences, and inform choices about its future direction. 


\section{DISCUSSION}

This manuscript described a system for evaluating community coalitions for the prevention of substance abuse. The evaluation system used eight measurement instruments to capture 15 different measures related to coalition process, outcome, and impact. The results suggest that Project Freedom contributed to: a) mobilizing the community, as evidenced by an increased rate of community actions by staff and coalition members, b) changing the community, as evidenced by increased changes in programs, policies, and practices related to substance abuse, c) changing youth behavior, including a small decrease in reported alcohol use, and d) having an impact on the community, as evidenced by a reduced rate of single-nighttime vehicle crashes.

A particularly intriguing finding is that the intermediate outcome of community change appears to be related to a widely recommended community-level indicator of substance abuse. This is important since community-level indicators, such as single-nighttime vehicle crashes, are often too delayed to enable useful and ongoing feedback on the functioning of substance abuse coalitions. This finding may be spurious; for instance, a particular event not reflected in the community changes (perhaps even unrelated to the coalition's efforts) may have been responsible for changes in this particular community-level indicator. Preliminary findings suggest that community changes may be an early marker of the ultimate impact of substance abuse coalitions. Future research will help establish whether, and

under what conditions, patterns of community change are predictive of changes in accurate and sensitive community-level indicators of substance abuse.

Other qualitative and quantitative data provide important secondary findings on coalition functioning. Survey data suggest that the coalition was satisfied with many aspects of the process, including the strength and competence of staff and the clarity of vision for the coalition. Other aspects, such as opportunities for members to take leadership roles, might be improved. 
Although policy changes were valued more than slight changes in practice, coalition members felt that the community changes were important to the mission. The coalition attained many of its original goals, also facilitating other changes in response to emerging opportunities. This may have contributed to moderate to high levels of satisfaction with the coalition among members. Some critical events, such as action planning and the onset and offset of key staff and leadership, appear to be related to coalition functioning.

Several challenges to evaluating community coalitions are implicit in this case study of a substance abuse coalition. First, the effects of coalition efforts are often delayed. Ultimate impacts, such as might be detected with community-level indicators, may not occur for several years. Reducing risk and enhancing protective factors is a more realistic aim of community coalitions. Accordingly, an important focus of the evaluation should be detecting community changes, alterations in programs, policies, and practices, that will potentially reduce risk or enhance protection from substance abuse. Such changes will not be of equal significance; their importance to the mission should be assessed by outcome surveys and interviews with key participants. Assessment of the effects of the coalition should be continued long enough to learn about the size and durability of impacts on community-level indicators.

Second, the usual research goal of establishing links between project activities (well specified independent variables) and particular outcomes (the dependent variables) may be particularly challenging. Community coalitions use a variety of strategies, such as networking and advocacy, to launch an array of interventions, such as mentoring programs and enhanced enforcement, each with multiple components. The interventions focus on different targets, such as youth and parents, and operate with different agents, such as religious leaders and business people. They are implemented in multiple community sectors, such as in schools and criminal justice, over varying periods of time. Accordingly, it is very difficult to specify the independent variable, its timing, and dosage. 
Some coalitions may commission intervention research studies ${ }^{16}$ to evaluate the effects of especially innovative or potentially powerful community changes. For example, Project Freedom carefully evaluated the effects of an intervention designed to reduce sales of alcohol

and tobacco to youth. ${ }^{17}$ In-depth analysis of all changes brought about by a coalition is time and cost intensive, however. Accordingly, care is needed in selecting potentially powerful changes in program, policy, or practice for intense study.

Finally, since coalition-induced changes in the community may affect the entire population, it is also difficult to obtain a suitable comparison group. It may be difficult to obtain data from other communities or find communities with similar characteristics. Since other communities may also be acting on the problem, they may serve as a comparison, but not as a control. Inadequate comparison communities may make it difficult to conclude that the results were due to the coalition and not something else. General statements about possible relationships between rates of community change and community-level indicators may be strengthened only by replication. Future longitudinal studies of multiple sites may help us discover the conditions under which community change is a valid predictor of community-level impact.

Although the monitoring system helps address some of these concerns, its use also poses some methodological challenges related to accuracy and sensitivity of reports, reactivity of measurement, and change in instrumentation. We address these challenges in several ways. First, we attempt to increase the accuracy and completeness of reports by using event logs and follow-up interviews with members and staff of the coalition. Second, honesty of reporting is encouraged by occasional verification by independent sources, such as meeting minutes and media reports. Third, we acknowledge that an even more sensitive reporting system would capture the offset of events, such as when a program concluded, as well as the onset of events which is the focus of this measurement system. Fourth, the monitoring system is highly reactive, as coalitions are asked to report activities monthly. Since monitoring and feedback are part of 
the design for this initiative, this is less a methodological flaw than a caution that the effects may be limited to these conditions. Fifth, monitoring is a time and cost intensive form of evaluation. Perhaps selection of fewer measures, or scheduled phone interviews in lieu of event logs, would reduce the costs to coalition staff and evaluators. Finally, we attempt to reduce changes in instrumentation by using a standard protocol that includes scoring instructions and behavioral definitions for each measure. Relatively high levels of agreement in scoring among independent observers suggest that reliable data can be produced with the monitoring system.

Despite these challenges, the systematic study of coalitions will likely continue to provide clues to the nature and functioning of community-based initiatives. Since we use adaptations of this evaluation system with other community initiatives, a multiple case study design is unfolding. Adapted versions of the Work Group's evaluation system have been used with eight health and human service coalitions in Massachusetts funded by the Kellogg Foundation, cardiovascular disease coalitions funded by the Kansas Health Foundation, and the Decade of Hope Coalition in Dulce, New Mexico, supported by the U.S. Center for Substance Abuse Prevention's Community Partnership Program. A replication of the Project Freedom model with three new substance abuse coalitions in Kansas, and of the South Carolina school/community model to prevent adolescent pregnancy ${ }^{18}$ with three communities in Kansas, provide valuable opportunities to discover the conditions under which such

initiatives can produce community change and impact. Ongoing and future efforts will help us understand the generality of this model for evaluating community coalitions and the utility of this approach to supporting community-based strategies for health and development.

\section{Implications for Health Education}

Although many millions of dollars have funded community coalitions for the prevention of substance abuse, there is little scientific evidence that this investment in the coalition strategy has had an impact. This comprehensive case study suggests that, at least under some conditions, 
community coalitions can have an impact on community-level indicators of substance abuse. Since community change appears to be correlated with eventual impact, it may be an important intermediate outcome that can be used by health educators to monitor and provide ongoing feedback on coalition functioning. Participatory evaluation helps us understand the variables that may affect the functioning of community health initiatives, enabling health educators and other change agents to use this information to improve their capacities to produce change. Such collaborative research strengthens both the science and practice of societal change. 


\section{REFERENCES}

Falco M: The making of a drug-free America. New York, Time Books, 1992.

Hawkins JD, Catalano RF, Associates: Communities that care. San Francisco, JosseyBass Publishers, 1992.

Fawcett SB: Some values guiding community research and action. J of Appl Behav Anal, 24:621-636, 1991.

Argyris C, Putnam R, Smith DM: Action science. San Francisco, Jossey-Bass Publishers, 1990.

Steckler A, McLeroy KR, Goodman RH, Bird ST, McCormick L: Toward integrating qualitative and quantitative methods: An introduction. Health Educ Q, 19:1-8, 1992.

Hugentobler MK, Israel BA, Scharman SJ: An action research approach to work place health: Integrating methods. Health Educ Q, 19:55-76, 1992.

Fawcett SB, Francisco VT, Paine AL, Richter KP, Lewis RK,Harris KJ, Williams EL, Berkley JY, Schultz JA: Work Group evaluation handbook: Evaluating community initiatives for health and development. Lawrence, KS, Work Group on Health Promotion and Community Development, University of Kansas, 1994.

Fawcett SB, Paine AL, Francisco VT, Vliet M: Promoting health through community development. In Glenwick D, Jason LA (eds), Promoting health and mental health in children, youth, and families. New York: Springer Publishing, 1993.

Green LW, Kreuter MW: Health promotion planning: An educational and environmental approach, 2nd ed. Mountain View, CA, Mayfield, 1991.

Francisco VT, Paine AL, Fawcett SB: A methodology for monitoring and evaluating community health coalitions. Health Educ Res: Theor and Prac, 8:403-416, 1993. 
Bakeman R, Gottman JM: Observing interaction: An introduction to sequential analysis. Cambridge University Press: NY, 1986.

Fawcett SB: Social validity: A note on methodology. J of Appl Behav Anal, 24:235-239, 1991.

Wolf MM: Social validity: The case for subjective measurement or how applied behavior analysis is finding its heart. J of Appl Behav Anal, 11:203-214, 1978.

Fawcett SB, Paine-Andrews A, Francisco VT, Richter KP, Lewis RK, Williams EL, Harris KJ, Winter-Green K: Preventing Adolescent Substance Abuse: An Action Planning Guide for Community-Based Initiatives. Lawrence, KS, Work Group on Health Promotion \& Community Development, University of Kansas, 1992.

ISA Associates: OSAP National Evaluation of the Community Partnership Demonstration Program: Evaluation Plan. Washington DC, Office for Substance Abuse Prevention, 1992.

Fawcett SB, Suarez-Balcazar Y, Balcazar FE, White GE, Paine AL, Blanchard KA, Embree MG: Conducting intervention research: The design and development process. In Rothman J, Thomas EJ, (eds), Intervention research: Design and development for human service. New York, Haworth Press, 1994.

Lewis RK, Paine AL, Francisco VT, Richter KP, Copple B, Copple J, Fawcett SB: Illegal Alcohol and Tobacco Sales to Minors: Effects of Citizen Surveillance and Feedback. Manuscript in preparation.

Vincent ML, Clearie AF, Schluchter MD: Reducing adolescent pregnancy through school and community-based education. J Am Med Assoc, 257:3382-3386, 1987.

\section{ACKNOWLEDGMENTS}


This work benefited from the patient counsel and support of collaborators, especially Mary K. Campuzano and Marni Vliet, senior program officer and senior vice president of the Kansas Health Foundation; Tom Wolff, Director of the Massachusetts Area Health Education Center's Community Partners Program; and Donna Bell, staff member of Project Freedom. Dan Schulte of DCCCA, a regional prevention center in Douglas County, provided valuable assistance with obtaining behavioral survey data. This work was supported in part by grants from the Kansas Health Foundation (\#9107004) to the Work Group on Health Promotion and Community Development, Schiefelbusch Institute for Life Span Studies, at the University of Kansas. The mission of the Kansas Health Foundation is to improve the quality of health in Kansas. Reprints may be obtained from the first author, Department of Human Development, 4001 Dole Building, University of Kansas, Lawrence, Kansas 66045.

\section{FIGURE LEGEND}

Figure 1 The framework used by the Work Group to evaluate process, outcome, and impact of substance abuse coalitions.

Figure 2 The cumulative number of community actions (e.g., telephone calls to key leaders) taken by Project Freedom. The boxes and arrows indicate the timing of critical events reported by key participants of the coalition.

Figure 3 The cumulative number of community changes (i.e., new or modified programs, policies, or practices) facilitated by Project Freedom.

Figure 4 The single-nighttime vehicle crash rate per 1000 for Sedgwick County, Wyandotte County (comparison county), and the State of Kansas. (The population is based on 1990 Census Data, U.S. Census Bureau). Single-nighttime vehicle crashes include vehicular accidents resulting in $\$ 500$ or more in property damage or any injury. [Source: Office of Traffic Safety, Kansas Department of Transportation.] 
Figure 5 The single-nighttime vehicle crash rate per 1000 in Sedgwick County and the cumulative number of community changes facilitated by Project Freedom.

${ }^{1}$ Falco (1992)

${ }^{2}$ Hawkins, Catalano, and Associates (1992)

${ }^{3}$ Fawcett "Values" piece (199X)

${ }^{4}$ Argyris, Putnam, and Smith (1990)

${ }^{5}$ Steckler et al. (1992)

${ }^{6}$ Hugentobler et al. (1992)

${ }^{7}$ Fawcett et al. (1994)

${ }^{8}$ Fawcett, Paine, Francisco, and Vliet (1993)

${ }^{9}$ Green and Kreuter (1991)

${ }^{10}$ Francisco, Paine, and Fawcett (1993)

${ }^{11}$ Bakeman and Gottman (1986)

${ }^{12}$ Fawcett (1991)

${ }^{13}$ Wolf (1978)

${ }^{14}$ Fawcett, Paine-Andrews, Francisco et al. (1992)

${ }^{15}$ ISA Associates (1992)

${ }^{16}$ Fawcett, Suarez-Balcazar et al. (1994)

${ }^{17}$ Lewis et al. (1994) 
${ }^{18}$ Vincent et al. - Murray's JAMA article 